\title{
Prevalence of lip sucking amongst 6-9-years old children
}

\author{
Ashley Ann Decruz*, Jakobus Runkat*, Syarief Hidayat* \\ *Department of Pedodontics Faculty of Dentistry Universitas Padjadjaran
}

\begin{abstract}
Oral habits in children are a common problem faced in the society. Lip sucking is one of such habit. Often overlooked, persistent lip sucking can bring upon deleterious effects upon the child's dentition. This research was aimed to identify the signs of lip sucking amongst 6-9 years old children. The research was descriptive using the survey technique and was conducted at Dental Hospital of Faculty of Dentistry Universitas Padjadjaran, Bandung, through observation for signs of lip sucking and filling up a survey form. A total of 100 children were examined in this research. From 100 children, 44 of them were identified to have at least one sign of lip sucking with 11 (25\%) children were aged 6 years old, 8 (18\%) children were aged 7 years old, 11 (25\%) children were aged 8 years old and as much as $14(32 \%)$ children aged 9 years old. The remaining 56 children examined were not found to manifest any signs of lip sucking. Based on the study can be concluded that the prevalence of lip sucking was $44 \%$.
\end{abstract}

Keywords: Lip sucking habit, 6-9 years old children.

\section{INTRODUCTION}

Recent times have witnessed a substantial increase of children being cared for by babysitters. The rising socioecomic status of Asia and the equally rising cost of living in Asian countries especially in the city, usually requires both parents in a family unit to work in order to support and provide for the family. This forces parents to send their children to a babysitter at a very young age. When being cared for by a baby sitter, an infant is usually fed through a bottle with an artificial nipple. This situation could lead to the lack of development of the sucking reflex. When this reflex is not allowed to develop adequately, sucking habits in children may continue late into the childhood and subsequently cause dental malocclusion. Therefore it is most important that the sucking reflex is allowed to be developed sufficiently through proper breastfeeding. Sucking can be generally categorized into two forms, the first being nutritive sucking and the second non-nutritive sucking. ${ }^{2}$ Nutritive sucking is a form of sucking that provides essential nutrients for humans while non-nutritive sucking is aimed at providing a sense of security, belonging and warmth and does not provide nutrients to the infant. An example of nutritive sucking occurs when an infant is breastfed and is receiving nutrient or food from its mother. Whereas nonnutritive sucking is observed when the infant sucks on digits, thumbs, lips, knuckles or objects such as pacifiers and blankets. Non-nutritive sucking usually occurs as a natural reflex to satisfy a child's need for contact or a sense of security. It is observed to occur in short and fast burst at 
a rate of two sucks per second in comparison with nutritive sucking that occurs at one suck per second which occurs at a slower pace. ${ }^{3}$ Lip sucking is categorized as a form of nonnutritive sucking. Similar to thumb sucking or pacifier sucking, when not outgrown at a certain age, lip sucking can contribute to improper dental development. Though not as prevalent as thumb or pacifier sucking, lip sucking is also frequently noted in children as a bad oral habit. ${ }^{4}$

When lip sucking becomes a regular habit in children, it has to be identified and proper prevention must be done in order to break the habit. In order to identify this habit certain clinical signs can be used as a gauge such as reddened or chapped lips, constant wetting of lips, teeth prints on lip, deepened chin sulcus, protrusion of upper front teeth or retrusion of lower teeth. ${ }^{4}$

The 6-9 years old age was chosen as it is the age when the child starts primary education and is trying to adapt to its new atmosphere. Based on the information above, it is expected that the habit of lip sucking is more prevalent during the start of the schooling period or during primary education. Besides that any bad oral habit should be treated before the eruption of the permanent dentition in order to prevent malocclusion. The age 6-9 years old is a mixed dentition period where intervention can be done to break the habit of lip sucking before it interferes with the permanent dentition. It is hoped that by identifying lip sucking in children, malocclusion can be prevented in the future. This research was aimed to identify the signs of lip sucking amongst 6-9 years old children.

\section{METHODS}

The data in this study were taken using a questionnaire to each patient aged 6-9 years old who came to the Pedodontics Clinic of Dental Hospital of Faculty of Dentistry Universitas Padjadjaran, Bandung. Each child was interviewed and checked for signs of lip sucking, such as reddening of lips, constant wetting of lips, and wrinkled or golf ball effect in the area of the symphysis. All forms are collected at the end of the day and the data collected was noted. This procedure is carried out for a span of 1 month.

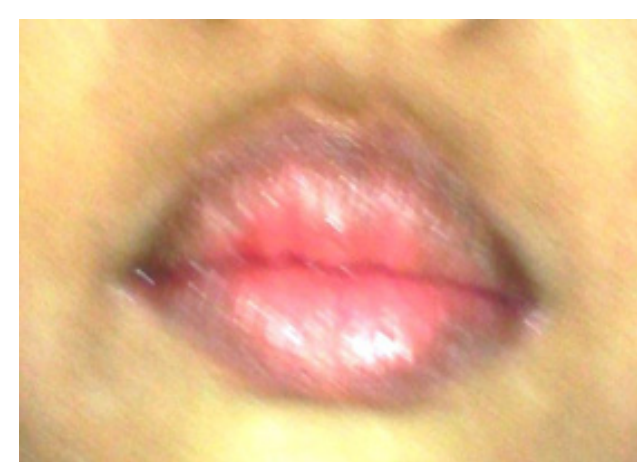

Figure 1. Reddening of lips 5

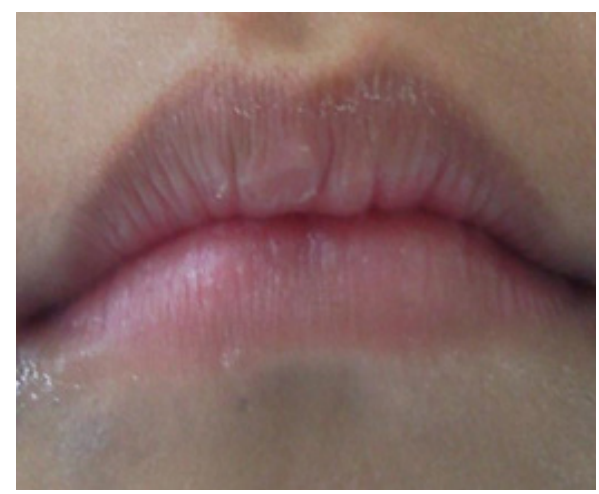

Figure 2. Chapping of lips ${ }^{5}$

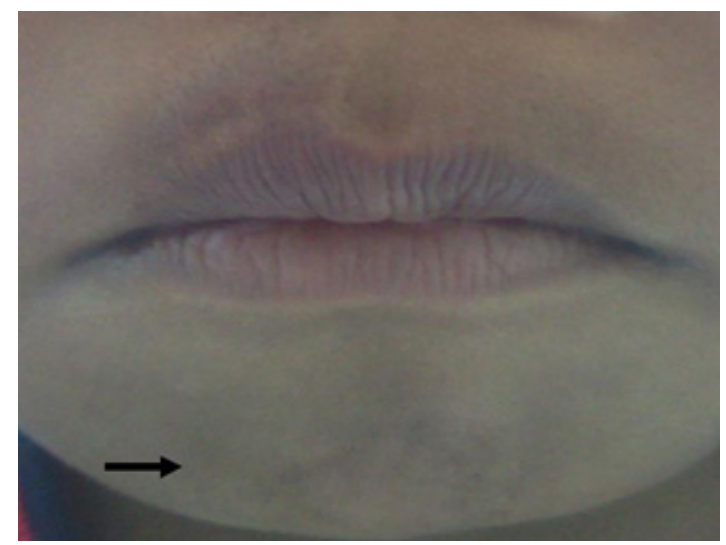

Figure 3. Wrinkled effect in the area of the symphysis $^{5}$

\section{RESULTS}

In this research, an examination was conducted among 100 children aged 6-9 years old consisted of boys and girls. Each subject was examined for the signs of lip sucking. If the subject was found to manifest any one of the 3 signs of lip sucking such as reddening of lips, constant wetting, dry or chapped lips and a wrinkled golf ball effect in the area of the symphysis, then the subject was categorized as having lip sucking habit 
Table 1. Distribution of lip sucking habit among 6-9 years old children

\begin{tabular}{|c|c|c|c|}
\hline & Results & $\begin{array}{c}\text { Total amount of } \\
\text { children }\end{array}$ & \\
\hline \multicolumn{2}{|c|}{$\begin{array}{l}\text { Children with } \\
\text { manifestation of lip } \\
\text { sucking habit }\end{array}$} & 44 & \\
\hline \multicolumn{2}{|c|}{$\begin{array}{l}\text { Children with no } \\
\text { manifestation of lip } \\
\text { sucking habit }\end{array}$} & 56 & \\
\hline \multicolumn{2}{|l|}{ Total } & 100 & 1 \\
\hline \multicolumn{4}{|l|}{60} \\
\hline \multicolumn{4}{|l|}{ so } \\
\hline \multicolumn{4}{|l|}{40} \\
\hline \multicolumn{4}{|l|}{20} \\
\hline \multicolumn{4}{|l|}{10} \\
\hline \multicolumn{4}{|l|}{0} \\
\hline & $\begin{array}{r}\text { Children w } \\
\text { Manifestation } \\
\text { Sucking }\end{array}$ & $\begin{array}{r}\text { Children with } \\
\text { Manifestation } \\
\text { Sucking }\end{array}$ & \\
\hline
\end{tabular}

Figure 4. Distribution of lip sucking habit among 6-9 years old children

Table 2. Distribution of lip sucking habit among 6-9 years old children based on gender

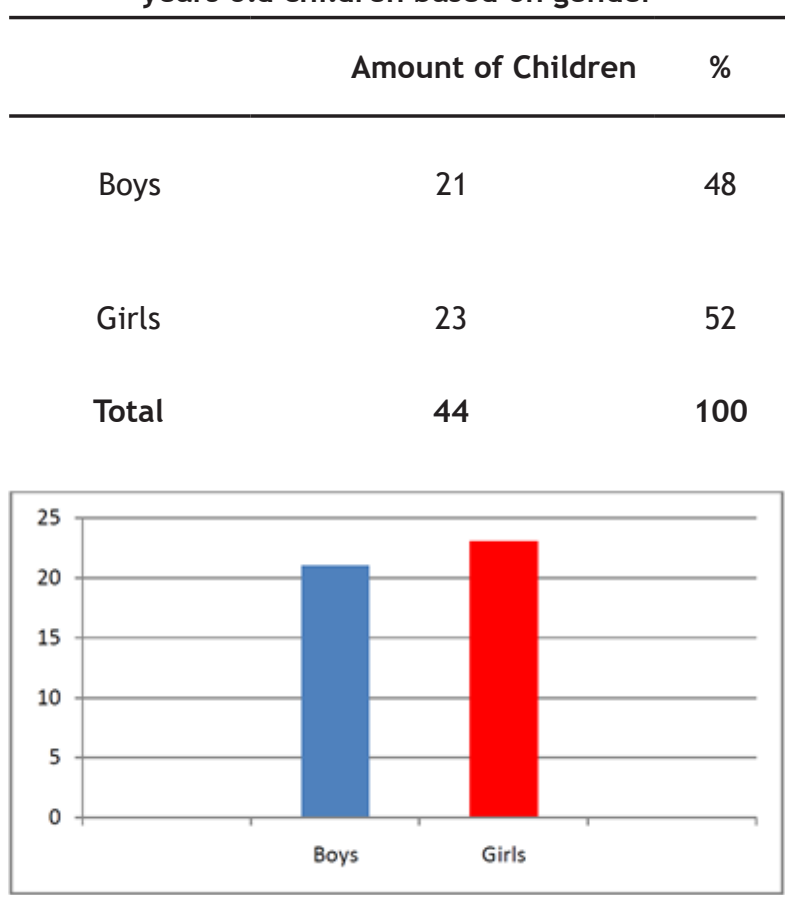

Figure 5. Distribution of lip sucking habit among 6-9 years old children based on gender

\section{DISCUSSION}

This research was aimed to identify the signs of lip sucking amongst 6-9 years old children. Based on the results obtained from this research a total of $44(44 \%)$ children from the total of 100 children examined were found to manifest signs of lip sucking. This percentage makes up a significant amount when compared to other researches for example a study conducted by Onyeaso in 2004 reported only about $1.2 \%$ of children with lip sucking. ${ }^{6}$

The results obtained also show that the highest numbers of lip suckers were found in the 9-years-old children (32\%), followed by 8 year olds and 6 year olds both representing $25 \%$ of the total sample. The least percentage is represented by 7 year olds with $18 \%$. This condition may be due to the fact that lip sucking usually occurs during a child's school age which usually starts around the age of 6 in most Asian countries. ${ }^{7}$ This habit was recorded to be highest among 9 year olds. This could be because the age 9 is considered as a preadolescent age and the child usually undergoes physiological changes as well as psychological, emotional and social implications. ${ }^{8}$ This can cause anxiety and stress which could lead to the habit of lip sucking. Oral habits that continue into the mix dentition period which starts around the 6-yearsold age can bring upon disfiguring consequences to a child's dentition.

Most children tend to suck their lips when they are nervous or anxious. This kind of lip sucking may not pose as a threat to the child's dental growth as the child only sucks his or her lips occasionally. However, certain lip sucking can be caused by muscle imbalance which usually results in incompetent lips and this makes the child more prone towards lip sucking. ${ }^{5} \mathrm{~A}$ few of the children examined during this research clearly exhibited negative lip seal or incompetent lips. These children when asked to purposely close their lips manifested a puckered skin effect on the chin.

Very often parents and children pay little attention to the habit of lip sucking with many not even realizing it or simply regarding it as a normal habit. There is little information on the habit of lip sucking, to which even practitioners attribute less clinical consequences It is important to always bear in mind that unhealthy oral 
habit like lip sucking may pose as an etiology of malocclusion as it affects the development of the orofacial region. ${ }^{5}$

From this research, it has also been observed that children generally tend to suck more on their lower lip. This is also known as a variation of lip sucking or also known as the mentalis muscle habit. In this condition, the lower lip is everted and only involves the vermilion border. This habit eventually results in an area of contraction between lips and chin that causes maxillary protrusion. There is also a relationship between the strong contraction of the lower lip orbicular muscle and the mentalis muscle associated with the hypertonicity of the upper lip that has to be balanced by the lingual thrusting during deglutition. Malocclusion due to persistent lip sucking can be prevented by intraoral devices such as lip bumpers or extraoral lip exercises such as lip on lip exercises. ${ }^{5,9}$

Other oral habits such as digit sucking, tongue thrusting or nail biting may cause embarrassment to a child if it continues into middle or late childhood. There is a possibility that these habits will cessate when a child starts to go to school due to peer pressure and self realization. However, lip sucking usually goes about unnoticed by many, thus early detection and prevention might be difficult.

Nevertheless, lip sucking can be detected when proper attention is given towards a child's oral habit. Parents and dentist should never regard lip sucking as something normal as it deserves no less attention compared to other oral habits. Due to the equally detrimental effects lip sucking can bring upon a child's occlusion, it is vital that proper attention is given in order to prevent this habit from causing malocclusion in children.

\section{CONCLUSION}

Based on the study can be concluded that the prevalence of lip sucking was $44 \%$.

\section{REFERENCES}

1. Coleta KED, Neto JSP, Magnani MBBA. The role of pediatrician in promoting oral health. Braz J Oral Sci. Oct-Dec 2005;4(15):904-10.

2. Turgeon-O'Brien H, Lachapelle D, Gagnon PF, Larocque I, Maheu-Robert LF. Nutritive and nonnutritive sucking habits: a review. ASDC J Dent Child. 1996 Sep-Oct;63(5):321-7.

3. Wooldridge MW. The 'Anatomy' of Infant Sucking. Midwifery. Dec 1986;2(4):164-71.

4. Hanson ML, Mason RM, Vaidergorn B. Orofacial Myology: International Perspectives. 2nd ed. Springfield, Illinois: Charles C Thomas Pub. Ltd.; 2003. p. 288-301, 317-8.

5. Barberia E, Lucavechi T, Cardenas D, Maroto M. An Atypical Lesion Resulting from the Unhealthy Habit of Sucking the Lower Lip: Clinical Case Study. J Clin Pediatr Dent. 2006 Summer;30(4):280-2.

6. Onyeaso $\mathrm{CO}$. Oral habits among $7-10$ year-old school children in Ibadan, Nigeria. East Afr Med J. 2004 Jan;81(1):16-21.

7. Finn SB. Clinical Pedodontics. 4th ed. Philadelphia: Saunders-Elsevier; 2003. p. 37085.

8. Daniels R. Nursing Fundamentals: Caring and Clinical Decision Making. 1st ed. Clifton Park: Delmar Learning; 2004. p. 349.

9. Singh G. Textbook of Orthodontics. 2nd ed. New Delhi: Jaypee Brothers Medical Publishers (P) Ltd.; 2007. p. 581-7. 